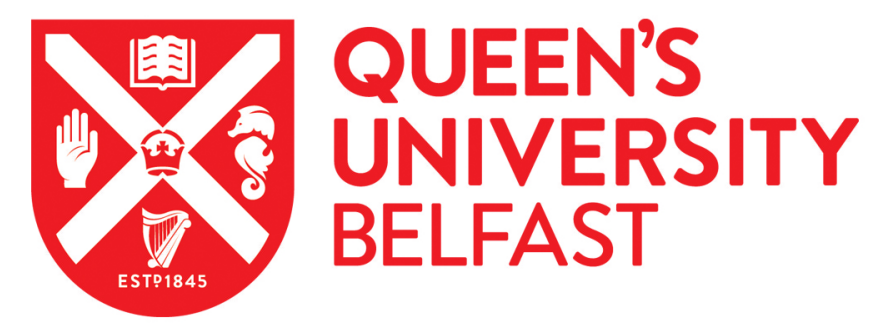

\title{
Percutaneous coronary intervention and 1 year survival in patients treated with fibrinolytic therapy for acute st-elevation myocardial
} infarction

McClelland, A. J. J., Owens, C. G., Walsh, S. J., McCarty, D., Mathew, T., Stevenson, M., Gracey, H., Khan, M. M., \& Adgey, A. A. J. (2005). Percutaneous coronary intervention and 1 year survival in patients treated with fibrinolytic therapy for acute st-elevation myocardial infarction. European Heart Journal, 26, 544-548. https://doi.org/10/1093/eurheartj/ehi149

\section{Published in:}

European Heart Journal

Queen's University Belfast - Research Portal:

Link to publication record in Queen's University Belfast Research Portal

\section{General rights}

Copyright for the publications made accessible via the Queen's University Belfast Research Portal is retained by the author(s) and / or other copyright owners and it is a condition of accessing these publications that users recognise and abide by the legal requirements associated with these rights.

Take down policy

The Research Portal is Queen's institutional repository that provides access to Queen's research output. Every effort has been made to ensure that content in the Research Portal does not infringe any person's rights, or applicable UK laws. If you discover content in the Research Portal that you believe breaches copyright or violates any law, please contact openaccess@qub.ac.uk. 


\title{
Percutaneous coronary intervention and 1 year survival in patients treated with fibrinolytic therapy for acute ST-elevation myocardial infarction
}

\author{
Anthony J.J. McClelland ${ }^{1}$, Colum G. Owens ${ }^{1}$, Simon J. Walsh ${ }^{1}$, David McCarty ${ }^{1}$, \\ Thomas Mathew ${ }^{2}$, Mike Stevenson ${ }^{3}$, Helen Gracey ${ }^{1}$, Mazhar M. Khan ${ }^{1}$, \\ and A.A. Jennifer Adgey ${ }^{*}$ \\ ${ }^{1}$ Regional Medical Cardiology Centre, Royal Victoria Hospital, Grosvenor Road, Belfast, BT12 6BA, Ireland \\ ${ }^{2}$ United Hospitals, Antrim, Ireland \\ ${ }^{3}$ Queen's University, Belfast, Ireland
}

Received 9 September 2004; revised 22 December 2004; accepted 29 December 2004; online publish-ahead-of-print 15 February 2005

See page 529 for the editorial comment on this article (doi:10.1093/eurheartj/ehi126)

\section{KEYWORDS}

ST-elevation myocardial infarction;

Primary percutaneous

coronary intervention;

Fibrinolytic therapy

\begin{abstract}
Aims To assess the predictors of 1 year mortality in patients treated with fibrinolytic therapy for ST-segment elevation myocardial infarction (STEMI) and to determine whether a strategy of early percutaneous coronary intervention (PCI) improves outcome. Methods and results Consecutive patients $(n=474)$ admitted to our unit (1998-2001) with STEMI were treated with fibrinolytic therapy. For each patient, age, gender, admission via mobile coronary care unit (MCCU), infarct location, initial systolic blood pressure and Killip class, prior history of ischaemic heart disease, hypertension, diabetes mellitus, smoking status, family history, hyperlipidaemia, and in-hospital PCI $(n=154)$ were recorded. Mortality at 1 year was obtained from medical records $(n=473)$. Binary logistic regression analysis was performed to determine independent predictors of 1 year mortality. Mortality in the non- $\mathrm{PCl}$ group was $21 \mathrm{vs.} 7 \%$ in the $\mathrm{PCl}$ group. Independent predictors of 1 year mortality were age (risk ratio $1.12,95 \% \mathrm{Cl} 1.08-1.15, P<0.0001$ ), initial $\mathrm{SBP} \leq 80 \mathrm{mmHg}$ (risk ratio $4.34,95 \% \mathrm{Cl} 1.68-11.2, P=0.002$ ), initial Killip class $\geq 3$ (risk ratio $2.97,95 \% \mathrm{Cl} 1.42-6.2, P=0.004$ ), and lack of in-hospital $\mathrm{PCl}$ (risk ratio 0.39 , $95 \% \mathrm{Cl} 0.19-0.81, P=0.012)$. Although the $\mathrm{PCl}$ group were younger $(P=0.007)$, more likely to be admitted via the MCCU $(P=0.008)$, with a shorter pain to needle time $(P=0.04)$, multivariable analysis adjusted for these differences.

Conclusion In-hospital PCl in patients treated with fibrinolytic therapy for STEMI is associated with a substantial reduction in 1 year mortality.
\end{abstract}

\section{Introduction}

The primary goal of treatment of acute coronary occlusion is the achievement of early, complete, and sustained epicardial and myocardial reperfusion. Until, recently,

*Corresponding author. Tel: +442890 633223/632171; fax: +44 2890 312907.

E-mail address: jennifer.adgey@royalhospitals.n-i.nhs.uk fibrinolytic therapy constituted the dominant approach for reperfusion in ST-segment elevation myocardial infarction (STEMI). Primary percutaneous coronary intervention $(\mathrm{PCl})$ is now used as an alternative to fibrinolysis with increasing frequency. This approach is supported by a recent comprehensive meta-analysis of 23 trials demonstrating that with primary $\mathrm{PCl}$, compared with fibrinolytic therapy, there were reductions in death, recurrent myocardial infarction, and stroke of 2, 4, and 1 per 100 
patients, respectively, through 4-6 weeks. ${ }^{1}$ However, the benefits of primary $\mathrm{PCl}$ are limited by the delays in treatment incumbent in this approach. In the meta-analysis by Keeley et al. ${ }^{1}$ there was no significant mortality benefit of emergency hospital transfer for primary $\mathrm{PCl}$ compared with on-site fibrinolysis. Furthermore, the PRAGUE-2 study randomized 850 patients with STEMI presenting within $<12 \mathrm{~h}$ to the nearest community hospital without a catheter laboratory to either fibrinolytic therapy (streptokinase) in that hospital ( $n=421)$ or immediate transport for primary $\mathrm{PCl}(n=429){ }^{2}$ Patients randomized within $3 \mathrm{~h}$ of symptom onset $(n=551)$ had no difference in 30 day mortality whether treated by fibrinolytic therapy $(7.4 \%)$ or transferred for $\mathrm{PCl}(7.3 \%){ }^{2}$ The Comparison of Angioplasty and Prehospital Thrombolysis In acute Myocardial infarction (CAPTIM) trial compared early, pre-hospital fibrinolytic therapy (with transfer to an interventional facility for possible rescue angioplasty) with primary $\mathrm{PCl}$ in 840 patients presenting within $6 \mathrm{~h}$ of onset of symptoms. ${ }^{3}$ Overall there was no benefit of primary $\mathrm{PCl}$ at preventing the composite endpoint of death, non-fatal re-infarction, or non-fatal stroke at 30 days. $^{3}$ In a further analysis of the data, it emerged that in patients treated with pre-hospital fibrinolytic therapy within $2 \mathrm{~h}$ of symptom onset, there was a strong trend toward lower 30 day mortality (2.2 vs. $5.7 \%$, $P=0.058)$ and a reduction of cardiogenic shock (1.3 vs. $5.3 \%, P=0.032$ ) compared with primary $\mathrm{PCl}^{4}{ }^{4}$ In the pre-hospital fibrinolytic arm of the CAPTIM trial, $26 \%$ of patients underwent rescue $\mathrm{PCl}$ for persistent ischaemia and $70 \%$ of patients had $\mathrm{PCl}$ by day 30 . Therefore, this study really compares a strategy of pre-hospital fibrinolytic therapy, transfer to an interventional centre, and subsequent $\mathrm{PCl}$ with primary $\mathrm{PCl} .{ }^{4}$ In addition, the lower mortality in the lytic group was sustained at 1 year. Although early studies on the use of $\mathrm{PCl}$ post-fibrinolytic therapy showed no benefit over a conservative approach, ${ }^{5}$ they were carried out before the era of stenting and modern antiplatelet therapy. It has thus recently been suggested that a therapeutic strategy that incorporates both fibrinolytic therapy and $\mathrm{PCl}$ will best serve most patients with STEMI. ${ }^{4,6}$

At present, there are very limited data available on this combined approach. From our registry of patients, we therefore aimed to assess the predictors of 1 year mortality in patients first treated with fibrinolytic therapy for STEMI either out of or in-hospital and to determine whether a strategy of early $\mathrm{PCl}$ (during in-hospital stay) would improve outcome.

\section{Methods}

\section{Patients}

Consecutive patients admitted with chest pain to the coronary care unit and cardiology wards of the Royal Victoria Hospital between February 1998 and March 2001 and who received fibrinolytic therapy for STEMI were reviewed. Patients transferred from other hospitals after acute myocardial infarction (AMI) for further investigations were excluded.
Data were collected prospectively and entered into a database (constructed using Microsoft Access) by a research nurse. The diagnosis of AMl was based on a suggestive history with STelevation $\geq 2 \mathrm{~mm}$ in two or more precordial leads, or ST-elevation $\geq 1 \mathrm{~mm}$ in two or more limb leads, or new left bundle branch block on the 12-lead electrocardiograph with a concomitant rise in creatine kinase $M B$ to $\geq 2$ times the upper limit of normal.

Patients were deemed eligible for fibrinolytic therapy up to $12 \mathrm{~h}$ from onset of symptoms. Contraindications to fibrinolytic therapy included hypertension $(>180 / 110 \mathrm{mmHg})$, prior stroke, recent major surgery/trauma, prolonged cardiopulmonary resuscitation, active bleeding, oral anticoagulation with warfarin, or haemorrhagic diathesis. Age was not a contraindication to fibrinolytic therapy. Invasive investigations and interventional treatment were at the discretion of the consultant cardiologist. As the unit participates in many international multi-centre fibrinolytic trials, varying fibrinolytic regimens were used during the study period.

The following data were noted on each patient: age, gender, history of hypertension, diabetes mellitus, hyperlipidaemia (cholesterol $>5.0 \mathrm{mmol} / \mathrm{L}$ ), smoking, family history (first degree relative with previous ischaemic heart disease), and whether the patient had a previous history of ischaemic heart disease/ myocardial infarction. The following characteristics were also noted: initial systolic blood pressure and Killip class, infarct location (based on the 12-lead electrocardiograph), symptom onset to needle time (time delay between onset of symptoms and administration of fibrinolytic therapy), admission via the mobile coronary care unit (MCCU) (with administration of prehospital fibrinolytic therapy) or not, and whether the patient underwent in-hospital $\mathrm{PCl}$.

Data for death, further $\mathrm{PCl}$, or coronary artery bypass grafting (CABG) at 1 year were obtained from hospital records (patient administration system) or by contacting the patient's general practitioner.

\section{Statistical analysis}

Categorical variables were compared with the Pearson's $\chi^{2}$ test and continuous variables with the independent samples $t$-test. Multivariable analysis was performed using forward, stepwise binary logistic regression to determine independent predictors of 1 year mortality. All variables (age, gender, admission via MCCU, infarct location, initial systolic blood pressure and Killip class, prior history of ischaemic heart disease, hypertension, diabetes mellitus, smoking status, family history, hyperlipidaemia, and in-hospital $\mathrm{PCl}$ ) were included in the multivariable analysis. The test also included a quadratic term for age, as linearity was not assumed. The test was repeated using only the univariate predictors of death. All tests were two-sided. $P<0.05$ was taken as significant. All means are shown with standard deviation and medians with interquartile range (25th-75th percentiles). All calculations were carried out with the SPSS version 10.0 software package.

The study complies with the Declaration of Helsinki and was approved by the Queen's University Of Belfast Research Ethics Committee. All patients gave informed consent.

\section{Results}

In the study period, 474 patients were treated with fibrinolytic therapy for STEMI. Mortality data were available for 473 patients with one lost to follow-up due to taking up residence in another country. Baseline demographics and clinical characteristics are shown in Table 1. 
Admission via the MCCU occurred in 256 (54\%) patients (Tables 1 and 2). Infarct locations were classified as anterior in 182 (38\%), inferior in 265 (56\%), and lateral in $26(6 \%)$ patients. The pain to needle time (median) was $3 \mathrm{~h}(1.9-5.1)$ with $378(80 \%)$ patients receiving fibrinolytic therapy within $6 \mathrm{~h}$. An initial systolic blood pressure $\leq 80 \mathrm{mmHg}$ occurred in $30(6 \%)$ patients, and 47 (10\%) had a Killip class $\geq 3$.

Table 1 Baseline demographics and clinical characteristics

\begin{tabular}{lc}
\hline Mean age $( \pm$ SD) & $64(12)$ \\
Male & $325(69)$ \\
Infarct location & \\
$\quad$ Anterior & $182(38)$ \\
Inferior & $265(56)$ \\
$\quad$ Lateral & $26(6)$ \\
Initial SBP $\leq 80 \mathrm{mmHg}$ & $30(6)$ \\
Initial Killip class $\geq 3$ & $47(10)$ \\
Admission via MCCU & $256(54)$ \\
Pain to needle time (median, h) & $3(1.9-5.1)$ \\
Previous AMI & $120(25)$ \\
Diabetes mellitus & $64(14)$ \\
Hyperlipidaemia & $318(67)$ \\
Hypertension & $139(29)$ \\
Current smoker & $199(42)$ \\
Family history of IHD & $290(61)$ \\
Thrombolytic agent & \\
Alteplase/reteplase/tenecteplase & $317(67)$ \\
Streptokinase & $156(33)$ \\
\hline
\end{tabular}

Data are number (\%) or median (interquartile range: 25 th and 75 th percentiles) or mean (SD). SBP, systolic blood pressure; IHD, ischaemic heart disease.
In-hospital $\mathrm{PCl}$ was carried out in 154 (33\%) patients (Table 2). The $\mathrm{PCl}$ group compared with the non- $\mathrm{PCl}$ group were younger $[62( \pm 11)$ vs. $65( \pm 13)$ years, $P=0.007]$, were more likely to be admitted via the MCCU [97 (63\%) vs. $159(50 \%), P=0.008]$, and had a shorter median pain to needle time $[2.5(1.7-4.0) \mathrm{h}$ vs. 3.9 (2.2-5.5) h, $P=0.04$ ]. In the $\mathrm{PCl}$ group, $86 \%$ of patients had fibrinolytic therapy within $6 \mathrm{~h}$ vs. $77 \%$ in the non- $\mathrm{PCl}$ group $(P=0.2)$. The $\mathrm{PCl}$ and non- $\mathrm{PCl}$ groups were also comparable with regard to gender, anterior/ inferior infarction, initial systolic blood pressure/Killip class, and history of previous AMI, diabetes mellitus, hyperlipidaemia, hypertension, current smokers, or family history of ischaemic heart disease. There was no difference in discharge medication between the groups except for the use of clopidogrel in the $\mathrm{PCl}$ group.

Angiographic data for the $\mathrm{PCl}$ group are summarized in Table 3. In the $\mathrm{PCl}$ group, 63 (41\%) patients underwent their procedure within $24 \mathrm{~h}$ of admission, with 27 (18\%) of these as 'rescue $\mathrm{PCl}$ ' because of persistent ischaemia.

One year outcomes (death/PCI/CABG) are summarized in Table 4. Death at 1 year occurred in 77 (16\%) of the 473 patients. Of the 378 who received lytic therapy within $6 \mathrm{~h}$ of the onset of symptoms, 133 had in-hospital $\mathrm{PCl}$ and 245 had no in-hospital $\mathrm{PCl}$ with a 1 year mortality of $7.5 \%$ $(10 / 133)$ and $18.8 \%(46 / 245)(P=0.004)$, respectively. Of the 95 patients who received lytic therapy $>6 \mathrm{~h}$ after onset of symptoms, 21 had in-hospital $\mathrm{PCl}$ and 74 had no in-hospital PCI with a 1 year mortality of $4.8 \%(1 / 21)$ and $27 \%(20 / 74)(P=0.036)$, respectively. Univariate predictors of 1 year mortality are shown in Tables 5 and 6. Age, initial Killip class $\geq 3$, initial systolic blood pressure $\leq 80 \mathrm{mmHg}$, no $\mathrm{PCl}$ in-hospital, female gender, non-smoking, and

Table 2 Demographics and clinical characteristics according to occurrence of in-hospital PCI

\begin{tabular}{|c|c|c|c|}
\hline & In-hospital PCI $(n=154)$ & No in-hospital PCI $(n=319)$ & $P$-value \\
\hline Mean age $( \pm S D)$ & $62(11)$ & $65(13)$ & 0.007 \\
\hline Admission via MCCU & $97(63)$ & $159(50)$ & 0.008 \\
\hline Pain to needle time (median, h) & $2.5(1.7-4.0)$ & $3.9(2.2-5.5)$ & 0.04 \\
\hline Fibrinolytic therapy $\leq 6 \mathrm{~h}$ & $133(86)$ & $245(77)$ & 0.2 \\
\hline Male & $113(73)$ & $212(67)$ & 0.2 \\
\hline Anterior AMI & $57(37)$ & $125(39)$ & 0.5 \\
\hline Inferior AMI & $93(60)$ & $172(54)$ & 0.5 \\
\hline Initial SBP $\leq 80 \mathrm{mmHg}$ & $10(6)$ & $20(6)$ & 0.2 \\
\hline Initial Killip class $\geq 3$ & $10(6)$ & 37 (12) & 0.3 \\
\hline Previous AMI & $40(26)$ & $80(25)$ & 0.9 \\
\hline Diabetes mellitus & $21(14)$ & $43(14)$ & 1 \\
\hline Hyperlipidaemia & $99(64)$ & $219(69)$ & 0.4 \\
\hline Hypertension & $47(31)$ & $92(29)$ & 0.7 \\
\hline Current smoker & $65(42)$ & $134(42)$ & 0.5 \\
\hline Family history of IHD & $98(64)$ & $192(60)$ & 0.5 \\
\hline \multicolumn{4}{|l|}{ Discharge medication } \\
\hline Aspirin & $137(89)$ & $290(91)$ & 0.8 \\
\hline$\beta$-Blocker & $109(71)$ & $233(73)$ & 0.7 \\
\hline ACE-inhibitor & $83(54)$ & $163(51)$ & 0.4 \\
\hline Statin & $112(73)$ & $220(69)$ & 0.7 \\
\hline Clopidogrel & 99 (64) & $6(2)$ & $<0.0001$ \\
\hline
\end{tabular}

Data are numbers (\%) or median (interquartile range: 25th and 75th percentiles). SBP, systolic blood pressure; IHD, ischaemic heart disease. 
Table 3 Angiographic data for in-hospital PCI group $(n=154)$

\begin{tabular}{lc}
\hline Indications for PCI & \\
Rescue PCI & $27(18)$ \\
Unstable angina & $37(24)$ \\
Post-AMI & $90(58)$ \\
Time from admission to PCl & \\
$0-24 \mathrm{~h}$ & $63(41)$ \\
$>24 \mathrm{~h}$ & $91(59)$ \\
Clinically significant coronary artery disease & \\
Single-vessel disease & $77(50)$ \\
Two-vessel disease & $43(28)$ \\
Three-vessel disease & $34(22)$ \\
Infarct related artery & \\
Left anterior descending artery & $59(38)$ \\
Circumflex artery & $17(11)$ \\
Right coronary artery & $78(51)$ \\
Left main stem & 0 \\
Intervention performed (stents) & \\
Single vessel & $145(94)$ \\
Two vessels & $9(6)$ \\
Angioplasty without stenting & 0 \\
\hline Data are numbers (\%). &
\end{tabular}

Table 4 1-Year outcomes (death/PCI/CABG) according to occurrence of in-hospital PCI

\begin{tabular}{lclc}
\hline Outcome & $\mathrm{PCl}(n=154)$ & $\mathrm{No} \mathrm{PCl}(n=319)$ & $P$-value \\
\hline Death & $11(7)$ & $66(21)$ & $<0.001$ \\
$\mathrm{PCl}$ & $8(5)$ & $57(18)$ & 0.001 \\
CABG & $5(3)$ & $13(4)$ & 0.7 \\
\hline \multicolumn{4}{r}{ Data are numbers (\%). }
\end{tabular}

Table 5 Univariate predictors of 1 year mortality (categorical variables)

\begin{tabular}{llrlc}
\hline Variable & & $n$ & Mortality & $P$-value \\
\hline Initial Killip & $<3$ & 426 & $58(14)$ & $<0.001$ \\
Class & $\geq 3$ & 47 & $19(40)$ & \\
Initial SBP & $>80 \mathrm{mmHg}$ & 443 & $64(14)$ & $<0.001$ \\
& $\leq 80 \mathrm{mmHg}$ & 30 & $13(43)$ & \\
In-hospital & Yes & 154 & $11(7)$ & $<0.001$ \\
PCI & No & 319 & $66(21)$ & \\
Gender & Male & 325 & $44(14)$ & 0.02 \\
& Female & 148 & $33(22)$ & \\
Current & Yes & 199 & $19(10)$ & 0.001 \\
Smoker & No & 274 & $58(21)$ & \\
Admitted via & Yes & 256 & $34(13)$ & 0.06 \\
MCCU & No & 217 & $43(20)$ & \\
\hline
\end{tabular}

Data are numbers (\%). SBP, systolic blood pressure.

a longer pain to needle time were associated with increased 1 year mortality. There was also a trend towards higher mortality in patients not admitted via the MCCU $(P=0.06)$. Previous history of hypertension,
Table 6 Univariate predictors of 1 year mortality (continuous variables)

\begin{tabular}{lccc}
\hline & Survived & Died & $P$-value \\
\hline Age (mean \pm SD) & $62(11)$ & $75(11)$ & $<0.001$ \\
Pain to & $2.9(1.9-4.8)$ & $3.6(1.9-6.3)$ & 0.03 \\
$\quad$ needle time & & & \\
(median and IQR) & & & \\
\hline
\end{tabular}

IQR, interquartile range (25th-75th percentiles).

Table 7 Independent predictors of 1 year mortality (multivariable analysis using binary logistic regression)

\begin{tabular}{lllc}
\hline & Risk ratio & $95 \% \mathrm{Cl}$ & $P$-value \\
\hline Age & 1.12 & $1.08-1.15$ & $<0.0001$ \\
Initial SBP $\leq 80 \mathrm{mmHg}$ & 4.34 & $1.68-11.2$ & 0.002 \\
Initial Killip class $\geq 3$ & 2.97 & $1.42-6.2$ & 0.004 \\
In-hospital PCI & 0.39 & $0.19-0.81$ & 0.012 \\
\hline
\end{tabular}

$\mathrm{Cl}$, confidence interval; SBP, systolic blood pressure.

diabetes mellitus, hyperlipidaemia, and AMI, family history, anterior/inferior infarction and treatment with lytic therapy within $6 \mathrm{~h}$ were not predictors of 1 year mortality.

All significant univariate predictors were included in the multiple logistic regression model to examine their independent predictive value for 1 year mortality (Table 7). Age, initial systolic blood pressure $\leq 80 \mathrm{mmHg}$, initial Killip class $\geq 3$, and no in-hospital $\mathrm{PCl}$ were significant independent predictors of 1 year mortality. Furthermore, the test also included a quadratic term for age $\left(\mathrm{age}^{2}\right)$ as linearity was not assumed with all variables remaining significant.

\section{Discussion}

The present study shows that patients treated with fibrinolytic therapy for STEMI who undergo in-hospital PCI have improved outcome (risk ratio $0.39,95 \% \mathrm{Cl}$ $0.19-0.81, P=0.012$ ) at 1 year compared with patients who do not undergo $\mathrm{PCl}$ (Table 7).

Although primary $\mathrm{PCl}$ is now used as an alternative to fibrinolytic therapy with increasing frequency, $<20 \%$ of patients presenting with STEMI are treated with primary $\mathrm{PCl}^{7}$ There remain some doubts about the overall superiority of primary $\mathrm{PCl}$ over fibrinolytic therapy. Melandri ${ }^{8,9}$ points out that although Keeley et al. ${ }^{1}$ report a significant $2.0 \%$ absolute reduction in total mortality in favour of primary $\mathrm{PCl}(P=0.0002)$. In the absence of the SHOCK trial, ${ }^{10}$ this difference falls to a non-significant $1.2 \%$ when comparing primary $\mathrm{PCl}$ with accelerated tissue plasminogen activator. There is also concern about the incumbent delays in transferring patients for primary $\mathrm{PCl}$. The median time delay (door to balloon time) in 661 centres was $1 \mathrm{~h} 56 \mathrm{~min}$, with 
nearly half of patients waiting $>2 \mathrm{~h}$ before balloon inflation, which was associated with an increase in inhospital mortality of $41-62 \%{ }^{11}$ A meta-analysis of published randomized trials of primary $\mathrm{PCl}$ vs. fibrinolytic therapy shows that when the time delay related to angiography (that is the door to balloon minus the door to needle time) is $>60 \mathrm{~min}$, the mortality benefits of primary $\mathrm{PCl}$ over thrombolytic therapy are lost. ${ }^{12}$ For every $10 \mathrm{~min}$ delay, there is a $1 \%$ reduction in impact of primary $\mathrm{PCl}$ on the composite endpoint of death, reinfarction, or stroke, so that by 90 min there is no measurable difference between primary $\mathrm{PCl}$ and immediate thrombolytic therapy. ${ }^{12}$

Some studies have suggested that combining early fibrinolytic therapy with subsequent $\mathrm{PCl}$ in the setting of STEMI may be a very effective strategy, ${ }^{13-16}$ particularly because it would reduce the time to optimal myocardial reperfusion compared with primary $\mathrm{PCl}$ and may reduce the risk of recurrent infarction compared with fibrinolytic therapy. This was particularly evident in the CAPTIM trial where pre-hospital fibrinolytic therapy within $2 \mathrm{~h}$ of symptom onset resulted in a strong trend toward lower mortality and a reduction of cardiogenic shock compared with primary $\mathrm{PCl}$ at 30 days. ${ }^{4}$ Also, the recently published GRACIA-1 trial randomized 500 patients with thrombolysed STEMI to angiography and intervention (if indicated) within $24 \mathrm{~h}$ of thrombolysis, or to an ischaemia-guided conservative approach. By comparison with patients receiving conservative treatment, by 1 year, patients in the invasive group had a $12 \%$ absolute reduction in the combined rate of death, re-infarction, or revascularization $(P=0.0008) .{ }^{17}$

Although our results are based on a multivariable analysis adjusting for many confounding variables, an observational study cannot adjust for all confounders. Nevertheless, our study lends support to the need for randomized controlled trials to determine whether primary $\mathrm{PCl}$ or a strategy incorporating fibrinolysis and $\mathrm{PCl}$ (facilitated $\mathrm{PCl}$, rescue $\mathrm{PCl}$, or delayed $\mathrm{PCl}$ ) best serves patients with STEMI.

\section{Acknowledgement}

A.J.J.M. and S.J.W. were funded by research fellowships from the Research and Development Office of the Northern Ireland Health and Social Services Agency and C.G.O. was funded by a fellowship from the Frances and Augustus Newman Foundation.

\section{References}

1. Keeley EC, Boura JA, Grines CL. Primary angioplasty versus intravenous thrombolytic therapy for acute myocardial infarction: a quantitative review of 23 randomised trials. Lancet 2003;361:13-20.

2. Widimsky P, Budesinsky T, Vorac D, Groch L, Zelizko M, Aschermann M, Branny M, St'asek J, Formanek P. Long distance transport for primary angioplasty vs. immediate thrombolysis in acute myocardial infarction. Final results of the randomized national multicentre trial-PRAGUE-2. Eur Heart J 2003;24:94-104.

3. Bonnefoy E, Lapostolle F, Leizorovicz A, Steg G, McFadden EP, Dubien PY, Cattan S, Boullenger E, Machecourt J, Lacroute J-M, Cassagnes J, Dissait F, Touboul P. Primary angioplasty versus prehospital fibrinolysis in acute myocardial infarction: a randomised study. Lancet 2002;360:825-829.

4. Steg PG, Bonnefoy E, Chabaud S, Lapostolle F, Dubien P-Y, Cristofini P, Leizorovicz A, Touboul P. Impact of time to treatment on mortality after prehospital fibrinolysis or primary angioplasty: data from the CAPTIM randomized clinical trial. Circulation 2003;108:2851-2856.

5. Michels KB, Yusuf S. Does PTCA in acute myocardial infarction affect mortality and reinfarction rates? A quantitative overview (metaanalysis) of the randomized clinical trials. Circulation 1995; $91: 476-485$.

6. Loubeyre C, Lefevre T, Louvard Y, Dumas P, Piechaud J-F, Lanore J-J, Angellier J-F, Le Tarnec J-Y, Karrillon G, Margenet A, Pouges C, Morice $M-C$. Outcome after combined reperfusion therapy for acute myocardial infarction, combining pre-hospital thrombolysis with immediate percutaneous coronary intervention and stent. Eur Heart J 2001;22:1128-1135.

7. Eagle KA, Goodman SG, Avezum A, Budaj A, Sullivan CM, LopezSendon J. Practice variation and missed opportunities for reperfusion in ST-segment-elevation myocardial infarction: findings from the Global Registry of Acute Coronary Events (GRACE). Lancet 2002;359:373-377.

8. Melandri G. Primary angioplasty or thrombolysis for acute myocardial infarction? Lancet 2003;361:965-966.

9. Melandri G. The obsession with primary angioplasty. Circulation 2003; 108:e162.

10. Hochman JS, Sleeper LA, Webb JG, Sanborn TA, White HD, Talley JD, Buller CE, Jacobs AK, Slater JN, Col J, McKinlay SM, LeJemtel TH. Early revascularization in acute myocardial infarction complicated by cardiogenic shock. SHOCK Investigators. N Engl J Med 1999;341:625-634.

11. Cannon CP, Gibson CM, Lambrew CT, Shoultz DA, Levy D, French WJ, Gore JM, Weaver WD, Rogers WJ, Tiefenbrunn AJ. Relationship of symptom-onset-to-balloon time and door-to-balloon time with mortality in patients undergoing angioplasty for acute myocardial infarction. JAMA 2000;283:2941-2947.

12. Nallamothu BK, Bates ER. Percutaneous coronary intervention versus fibrinolytic therapy in acute myocardial infarction: is timing (almost) everything? Am J Cardiol 2003;92:824-826.

13. Ross AM, Coyne KS, Reiner JS, Greenhouse SW, Fink C, Frey A, Moreyra E, Traboulsi M, Racine N, Riba AL, Thompson MA, Rohrbeck S, Lundergan CF. A randomized trial comparing primary angioplasty with a strategy of short-acting thrombolysis and immediate planned rescue angioplasty in acute myocardial infarction: the PACT trial. J Am Coll Cardiol 1999;34:1954-1962.

14. Juliard J-M, Himbert D, Cristofini $P$, Desportes J-C, Magne $M$, Golmard J-L, Aubry P, Benamer H, Boccara A, Karrillon GJ, Steg PG. A matched comparison of the combination of prehospital thrombolysis and standby rescue angioplasty with primary angioplasty. $\mathrm{Am} \mathrm{J}$ Cardiol 1999;83:305-310.

15. Lundergan CF, Reiner JS, Ross AM. How long is too long? Association of time delay to successful reperfusion and ventricular function outcome in acute myocardial infarction: the case for thrombolytic therapy before planned angioplasty for acute myocardial infarction. Am Heart J 2002;144:456-462.

16. Schweiger MJ, Cannon CP, Murphy SA, Gibson CM, Cook JR, Giugliano RP, Changezi HU, Antman EM, Braunwald E. Early coronary intervention following pharmacologic therapy for acute myocardial infarction (the combined TIMI 10B-TIMI 14 experience). Am J Cardiol 2001;88:831-836.

17. Fernandez-Aviles F, Alonso JJ, Castro-Beiras A, Vazquez N, Blanco J, Alonso-Briales J, Lopez-Mesa J, Fernandez-Vazquez F, Calvo I, Martinez-Elbal L, San Roman JA, Ramos B. Routine invasive strategy within 24 hours of thrombolysis versus ischaemia-guided conservative approach for acute myocardial infarction with ST-segment elevation (GRACIA-1): a randomised controlled trial. Lancet 2004;364:1045-1053. 